\title{
O PARENTESCO COMO CONSCIÊNCIA HUMANA: O CASO DOS PIRO
}

Peter Gow 1

\begin{abstract}
Nada de minha substância vos esteve oculto,
Quando fui formado no mistério,

Quando fui tramado nas profundezas da terra, Vossos olhos viam meu corpo informe.
\end{abstract}

(Salmos, 138:15)

Neste artigo, analiso o sistema de parentesco dos Piro da Amazônia peruana como um sistema autopoiético, isto é, como um sistema que gera suas próprias condições de existência. M eu argumento é que o parentesco piro emerge espontaneamente do interior das estruturas da consciência humana; é isso que responde pela possibilidade de sua existência, e que o torna potencialmente inteligível para pessoas como o presente autor e, espero, como os eventuais leitores deste trabalho.

Persigo aqui três objetivos. Primeiro, pretendo fornecer uma explicação do parentesco piro algo mais profunda que aquela presente em meus trabalhos anteriores. Segundo, desejo tornar mais explícito um postulado teórico que subjaz a esses trabal hos, a saber, que o parentesco é, acima de tudo, um sistema de subjetividade, pois as estruturas básicas da consciência humana envolvem necessariamente a consciência de um eu [self] em meio aos outros. Terceiro, e este é meu objetivo mais ambicioso, quero recuperar para a antropologia simbólica o conceito de natureza humana. Os dois primeiros pontos serão explicitamente desenvolvidos no artigo, enquanto o terceiro só será abordado na conclusão.

O estudo antropológico do parentesco está, hoje em dia, bastante fora de moda. Isto me parece trágico, pois privou nossa disciplina de um de seus objetos mais fecundos. Haverá, certamente, muitos motivos a explicar por que os antropólogos não se sentem mais interessados pelo parentesco; mas estou, aqui, menos preocupado com tais motivos que com tudo que se perdeu com semelhante desinteresse. 
Em que consiste, exatamente, a análise do parentesco? Quando Lewis Henry Morgan a inventou, em meados do século passado, ele procurava responder a uma questão, que pode ser assim parafraseada: como é possível que outros seres humanos, ao pensar sobre os aspectos mais íntimos e importantes da existência, saiam-se com idéias tão dramaticamente conflitantes com as minhas próprias? Se descendemos todos dos mesmos ancestrais, o que faz com que esses outros humanos não compartilhem minha compreensão desse laço fundamental? (ver Trautmann 1987)

Para M organ, essa unidade (da humanidade) na diversidade (do parentesco) era profundamente perturbadora, pois humanidade e parentesco eram uma coisa só. Um século mais tarde, Lévi-Strauss reformulou o problema:

“A idéia [...] segundo a qual a família biológica constitui o ponto de partida
utilizado por toda sociedade para elaborar seu sistema de parentesco não é,
decerto, exclusiva do mestre inglês [Radcliffe-Brown]. Há poucas outras
idéias, atualmente, capazes de obter maior unanimidade. Não há, tampou-
co, nenhuma outra tão perigosa, em minha opinião [...]. Um sistema de
parentesco não consiste nos laços objetivos de filiação ou de consangüinida-
de entre os indivíduos. Ele só existe na consciência dos homens; é um siste-
ma arbitrário de representações, e não o desenvolvimento espontâneo de
uma situação de fato" (Lévi-Strauss 1958 [1945]:61).

Passado quase meio século, com uma biologia transformada radicalmente, essa questão não perdeu nada de sua relevância; mas ela pode agora ser novamente reformulada. Sabemos hoje uma quantidade impressionante de coisas sobre os aspectos mais íntimos e importantes da vida quotidiana de outras espécies, sobretudo dos outros primatas. Pensemos, por exemplo, nos estudos de Goodall sobre os chimpanzés (Chimpanzees of Gombe), de Cheney e Seyfarth sobre o Cercopithecus aethiops (How M onkeys See the World), de Smuts sobre os babuínos (Sex and Friendship among Baboons), ou no livro de Shirley Strum, Almost Human. Quanto mais aprendemos sobre os não-humanos, menos certos ficamos de nossa distintividade como espécie. M as todo esse novo conhecimento parece nos ter causado um certo mal-estar. Assim, Donna Haraway, em seu livro Primate Visions, trava um combate feroz em favor da idéia de uma intencionalidade [agency] humana especial, apelando para argumentos relativos à representação, à história e ao poder discursivo. Como nunca se pôde oferecer uma prova cabal de que os chimpanzés, os 
babuínos ou os macacos langur se ocupam de representações, procedem a historicizações ou se entregam a práticas discursivas, então tais modos de intencionalidade só podem ser exclusivamente humanos. Haraway não tem nenhuma dificuldade em denunciar, apontando sua vinculação com imagens culturais poderosas e perigosas, a falsa inocência de uma fotografia que mostra um gesto afetuoso de intimidade entre J ane Goodall e um chimpanzé. Mas há uma questão que Haraway deixa sem resposta: o que estaria fazendo o chimpanzé nessa fotografia? O que estaria passando em sua mente, ou pelo menos naquilo que passa por ser sua mente?2

Com efeito, essas novas descobertas acerca da socialidade nãohumana são de molde a provocar um profundo mal-estar, se você for um humanista clássico. Pois elas sugerem uma conclusão simples, mas dolorosa para nosso orgulho. Nas palavras de Robert Foley, os humanos não são a espécie ímpar, primeira aos olhos de Deus ou proprietária exclusiva da Razão, mas apenas mais outra espécie ímpar. A humanidade dos humanos é tão especial como a lupinidade dos lobos ou a ostritude das ostras.

A o mesmo tempo, parece estar-se formando um consenso, entre os biólogos, segundo o qual a linguagem e certas formas de consciência seriam atributos específicos dos humanos. A tributos, não privilégios específicos. As línguas naturais de tipo humano parecem ser genuinamente exclusivas de nossa espécie; não se conhece nada de remotamente semeIhante entre os animais, sequer entre os demais membros da superfamília Hominoidea. A consciência, entretanto, sob as formas da consciência de si e da existência de outrem, parece ser comum aos Hominoidea, como por exemplo os humanos, os chimpanzés e os gorilas. Sua existência não parece ter sido demonstrada de modo convincente em babuínos ou em macacos vervet - e muito menos em lobos ou ostras, tanto quanto eu saiba.

Se olharmos para os Hominoidea, então, achamos a consciência. Os excelentes estudos de Premack sobre a mente dos chimpanzés, entretanto, indicam uma diferença fundamental entre a consciência desses animais e a humana: os chimpanzés são conscientes [aware] de si mesmos, e de outrem, mas não parecem ser conscientes da consciência que os outros têm deles mesmos. Esse tipo de recursividade generalizada da consciência parece ser exclusivo dos humanos, e, como sugere Premack, está provavelmente associado de modo estreito à linguagem.

A questão, portanto, não é a de se compensar negativamente nossos sentimentos de superioridade, denegrindo os atributos ímpares de nossa espécie só porque o modo como os humanos têm tratado as outras espé- 
cies (e a si mesmos) nos consterna. Todo aquele que já tenha olhado faminto para uma árvore da floresta tropical carregada de frutos, já experimentou uma inveja lancinante dos atributos ímpares dos macacos-aranha ou dos chimpanzés. O mesmo se diga de quem quer que já tenha contemplado um gato no inverno europeu, alegremente "descalço" na neve lá fora enquanto trememos de frio dentro de nossas casas e agasaIhos. Afinal de contas, a linguagem só serve para se falar com ela, e o mesmo vale para a consciência. Como veremos, a consciência e a linguagem piro se constituem a partir dessa experiência quotidiana dos atributos únicos das outras espécies vivas.

É nesse contexto geral que desejo explorar a questão de M organ, tomando o parentesco piro como consciência humana. O que faz com que os Piro, ao pensarem sobre os aspectos mais íntimos e importantes de suas relações com outrem, guiem-se por idéias tão dramaticamente conflitantes com as minhas próprias? E como essas idéias se associam à linguagem?

Para responder a estas perguntas, sigo a trilha aberta por uma série de críticas perspicazes à análise lévi-straussiana do parentesco, que apontaram uma deficiência crucial nessa abordagem: a incapacidade de levar realmente em conta o papel constitutivo da subjetividade no parentesco. Estou-me referindo às críticas de Anthony Wilden e Gayle Rubin, inspiradas na reformulação lacaniana da teoria de Lévi-Strauss. M as sigo também uma observação decisiva de Marylin Strathern, que, desenvolvendo os argumentos de Wilden e Rubin, associa o fracasso da análise de Lévi-Strauss ao uso da teoria maussiana do dom para explorar o parentesco como uma estrutura da consciência humana 3 .

Prossigo aqui uma análise que publiquei há alguns anos sobre esse problema (Gow 1989), mas agora buscando chegar mais perto de seu centro, mediante um ol har mais atento ao modo específico pelo qual a subjetividade é pressuposta, e posta, no e pelo mundo vivido piro. Esse trabaIho anterior concentrava-se na questão de saber que espécies de sujeitos podem existir em uma economia como a dos Piro. A crescento a isto, agora, a questão de saber como a subjetividade pode vir a existir em geral.

Estou razoavelmente seguro de que minha análise pode se aplicar a qualquer sociedade humana ${ }^{4}$. Escol hi os Piro porque este é o mundo vivido al heio com que tenho maior familiaridade, desde que comecei meu trabalho de campo junto a eles, em 1980. Os Piro são um povo indígena de língua aruaque (ramo maipureano) distribuído em quatro áreas da A mazônia Ocidental, ao longo dos rios Urubamba, Cushabatay, Manú e Iaco. Conheço melhor os habitantes do Baixo Urubamba, no Peru. Eles 
vivem em aldeias que abrigam entre cinquenta e trezentas pessoas (exceto no caso da missão El Rosario de Sepahua, com mais de mil pessoas), obtendo sua subsistência da agricultura itinerante, da pesca e da caça, bem como do trabalho para as madeireiras e outras atividades remuneradas. Todos os Piro mantêm relações intensas com povos não-Piro como os Campa-A sháninka, os M achiguenga e os mestizos. O leitor poderá encontrar maiores informações em minha monografia sobre os Piro (G ow 1991).

Advirto que a descrição e análise do parentesco piro apresentadas a seguir podem ser um tanto difíceis de acompanhar. Isto é uma conseqüência lógica da tese enunciada mais atrás, a saber, que o parentesco piro é um sistema autopoiético: como ele dá origem a si mesmo, não há ponto privilegiado por onde se entrar nele, nem caminhos predeterminados para se o percorrer. Só me resta esperar que, ao cabo da leitura destas páginas, a lógica de tipo "passeio aleatório" [random-walk] de minha abordagem tenha se tornado clara, e, sobretudo, que a lógica do parentesco piro tenha sido compreendida.

\section{Falar ou não falar}

Quando se vai contar uma história complicada, é melhor começar pelo princípio. Para os Piro, o princípio está nas tsrunnini ginkakle, aquelas "histórias dos antigos" que os velhos às vezes contam para seus netinhos ao cair da noite. Os antropólogos não teriam muita dificuldade em identificá-las como mitos. Há muitas delas, e nenhum Piro afirmaria que sabe todas. Os velhos as conhecem apenas porque seus próprios avós as recitavam para eles, quando eles eram crianças. Não temos meios de saber, e os Piro tampouco, qual começo é o verdadeiro começo; portanto, como um narrador Piro, principio pela história mais afim ao meu tema 5 .

Muchikawpotgimni sato yinero ganurutatka wa mgenoklu.

"Há muito tempo, dizem, uma mulher casou-se com um jaguar".

Esta é a sentença inicial de uma versão da "história dos antigos" que podemos chamar aqui de "O Nascimento de Tsla". A história conta que essa mulher andava, certo dia, na floresta, quando o fil ho que trazia no ventre, falando-lhe, conduziu-a até a casa do marido. Ali, os afins-jaguar da mulher a mataram e devoraram, mas a sogra guardou o útero grávido, do qual emergiram Tsla e seus irmãos. Estes, mais tarde, vieram a vingar 
a morte da mãe, fracassando apenas em suas tentativas de matar sua avó, que estava grávida. Os episódios subseqüentes mostram Tsla e seus irmãos criando os elementos básicos da existência piro. Tsla criou os humanos, em suas formas primárias de yine, "Humanos verdadeiros", e de kajine, "Brancos", a partir de dois tipos de argila de olaria.

Tudo que nós precisamos saber sobre o parentesco dos Piro está contido na narração dessa curta história, porque tudo que eles precisam saber está contido nesse evento. Isto é, tudo que não está na história está na relação entre o narrador e os ouvintes, e vice-versa. J á na história temos maridos e mulheres, mães e filhos, pais, tios, avós e parentes afins. E, sobretudo, temos a linguagem, usada por Tsla para dar o estranho conseIho intra-uterino à sua mãe.

Os processos sociais piro, e portanto o parentesco piro, podem ser caracterizados como a transformação de Outros em Humanos, e de Humanos em Outros, ao longo do tempo. Para os Piro como um todo, esses processos de transformação começaram no "há muito tempo atrás" das narrativas míticas, quando o mundo foi feito, e terminarão em algum momento no futuro, quando o mundo acabar. Para qualquer pessoa piro, tal processo principia com a fabricação de Humanidade logo após o nascimento, e termina com a produção de Alteridade logo após a morte. Para o povo Piro, essa série complexa de processos foi iniciada pelos giyaklune, os seres míticos; e a fala é o meio pelo qual se toma conhecimento disso.

Tsrunnini ginkakle, "histórias da gente de antigamente", são uma forma muito especializada de discurso, pois elas são a corporificação plena da temporalidade humana na fala. Sabem-se essas histórias porque elas foram contadas pelos tsrunni, "a pobre gente vel ha e morta" - os antepassados desconhecidos dos Piro hoje vivos. Tudo que os vivos sabem dos tsrunni Ihes chega somente através das histórias a seu respeito contadas pelas pessoas mais vel has. Os vel hos são a fonte dessas histórias porque eles próprios conviveram com pessoas mais próximas, no tempo, dos tsrunni. Mas mesmo os velhos não sabem realmente dos tsrunni, pois nunca os viram. Clotilde Gordón, de 80 anos, assim respondeu a uma de minhas perguntas sobre eles, que Ihe fiz no verão passado:

“Eu não sei; nunca vi a gente de antigamente. Só sei o que minha avó me ensinou quando eu era menina pequena. Só sei o que vi minha avó fazer".

O que gente como a vel ha Clotilde diz, entretanto, é a única fonte sobre os tsrunni acessível aos jovens. A penas o que os vel hos contam (ginkaka) aos jovens sobre os tsrunni constituirá seu conhecimento sobre 
estes. Os tsrunni existem apenas na fala dos velhos. É isso que torna as tsrunnini ginkakle tão notáveis: elas são o discurso citado de seres que só existem no discurso citado dos velhos. Dessa forma, as narrativas míticas são um tipo de superfala, ou, nos termos de Lévi-Strauss, "elas são mensagens que nos chegam, a rigor, de lugar nenhum". São os velhos, os tsrune, que conhecem esse discurso, sendo os únicos capazes de lhe dar a forma de fala6.

A relação dos ouvintes com a linguagem é muito diferente. Eles são crianças pequenas, que pouco sabem, e seus modos primários de linguagem visam a comunicação de seus desejos e necessidades legítimas aos mais velhos. Sua linguagem básica consiste em termos de parentesco como (a lista é exaustiva) mama, "mamãe", papa, "papai", jiro, "vovó", totu, "vovô", shapa, "titia", koko, "tio", e yeye, "irmã/o mais vel ho/a"7. $\mathrm{O}$ uso de tais termos demonstra que a criança é dotada de nshinikanchi, "mente, inteligência, memória, respeito, amor". Esta qualidade, nshinikanchi, pode ser despertada por certos atos das pessoas mais velhas, mas não pode ser ensinada à criança; ela precisa se desenvolver espontaneamente. Sua manifestação primeira e mais importante é a fala inteligível; o uso de termos de parentesco para se obter atenção e cuidado é o aspecto mais saliente e poderoso dessa capacidade.

Q uando os velhos contam "histórias dos antigos" para seus netos, tanto o narrador como os ouvintes estão demonstrando seu nshinikanchi: as crianças, ao mostrar interesse no desenrolar da narrativa; os velhos, pelo ato mesmo de contar a história, pelo fato de estarem vivos para contá-la, e de ter netos vivos a quem contá-la. Voltarei a esse ponto, depois de discutir o mito.

No pequeno fragmento do mito transcrito acima, a mãe de Tsla é designada pela palavra yinero. Essa palavra é o feminino singular de yine, "gente, Piro, seres humanos". Assim, a personagem é marcada como "mulher humana"; sua feminilidade é uma característica secundária que serve para estabelecer a valência da relação posterior com o Outro: aqui, a Humanidade está para a Alteridade como o afim do sexo feminino está para o afim do sexo masculino. M genoklu, o "jaguar", por sua vez, condensa a multiplicidade do O utro nessa figura do mais perigoso dos mamíferos selvagens, símbolo de toda competição inteligente e mortal pelo mundo vivido imediato.

A história diz respeito a um mau casamento e suas conseqüências. O bestialismo, o congresso sexual entre Humano e Outro, é perigoso, trazendo efeitos desastrosos para os implicados. Humanos devem casar-se com humanos, pois a mútua compreensão depende de uma comum natu- 
reza. O acontecimento que leva os jaguares a matar e comer a mãe de Tsla é a ânsia de vômito que a toma ao morder um piolho do marido; pois os piolhos do jaguar são enormes, "como besouros papaso, não como os pequenos piol hos dos humanos". Catar os piolhos do parceiro é um dos aspectos mais íntimos da vida conjugal; a esposa humana revela sua alteridade ontológica em relação ao marido jaguar ao enojar-se com a natureza deste. Marido e mulher devem ser o mesmo, ambos devem ser Humanos.

Mas eles não podem ser exatamente o mesmo. Há algo a que os Piro muito raramente aludem, uma possibilidade que ronda ameaçadoramente seu mundo social: o incesto. Que eu saiba, nenhuma narrativa mítica trata dessa questão8; nenhum Piro, tampouco, jamais a discutiu comigo, exceto no caso de suas formas menos graves, como o intercurso sexual entre padrasto e enteada - e mesmo assim para evocar as conseqüências horrendas que se abateriam sobre os culpados. Nada ouvi sobre relações mãe-filho e sogra-genro, e o intercurso entre irmão e irmã só me foi mencionado para indicar que ele seria uma prática dos mashko, um povo distintamente não-humano que vive muito longe, a sudeste9. Dizia-se dos mashko: "eles não são humanos, são bichos do mato!"

Não é simplesmente que os Piro não falem sobre o incesto; é que o incesto parece ser o oposto da linguagem. Matteson, uma missionárialingüista do SIL [Summer Institute of Linguistics], que começou a trabaIhar entre os Piro no final dos anos 40, faz o seguinte registro: “Quando se sugeriu que um menino se casasse com a filha de seu tio paterno, sua mãe Ihe disse: 'M as como, você seria capaz de casar com sua irmãzinha, com a filha de seu pai mais moço? Você é mesmo um cachorro! Você não é gente de jeito nenhum!" (M atteson 1955: 80)10.

Ora, um certo mito piro conta que, antigamente, os cachorros podiam falar, mas que perderam essa habilidade por terem desrespeitado um tabu (que o mito não diz qual é). Hoje em dia, as relações entre humanos e cachorros se reduzem à "linguagem" elementar das ordens dadas pelos primeiros e dos variados uivos, latidos e rosnados dos segundos. Isto sugere que o tabu quebrado pelos cães da antiguidade é aquele que incide sobre as relações incestuosas, e que o preço da quebra do tabu é a perda da linguagem. $\mathrm{O}$ incesto e a linguagem são estados mutuamente exclusivos: os Piro não falam sobre o incesto porque ele é, literalmente, "indizível".

No mito, Tsla fala à sua mãe de dentro do útero, visando fazê-la tomar a direção errada. N este ponto, os narradores costumam observar: "Kgiyaklewakleru wa Tsla", "Tsla era um transformador miraculoso". 
Giyaklewata, "transformar miraculosamente", é um modo de ação completamente desconhecido dos Piro contemporâneos. Só sabem dele pelas histórias: é o modo de ação característico dos seres míticos e dos brancos desconhecidos que moram em terras distantes. Na primeira vez em que usa tal poder no mito, Tsla fala à mãe para levá-la à perdição nas garras dos J aguares ${ }^{11}$. A través desse ato incestuoso, esse falar intra-uterino à sua mãe, Tsla lhe causa a morte.

\section{0 corte do cordão umbilical}

O que há de miraculoso, do ponto de vista piro, em um feto falante? É preciso aqui olharmos mais de perto para as ontogenias do feto e da linguagem.

Os Piro têm idéias muito próprias sobre o feto; mais que isso, eles têm idéias muito próprias sobre as idéias que o feto tem. Ou melhor, eles têm idéias próprias a respeito do que seria o mundo oculto dos fetos dos fetos que, ao contrário de Tsla, não são dados à conversação - , tal como revelado pelas fases posteriores do desenvolvimento infantil.

O que é um feto? Um feto é manewlu, "aquilo que está tendo um corpo feito", "aquilo que está sendo encorporado"* . Ele é o paciente da ação verbal manewata, "dar forma substancial a", "fazer um corpo para". Por um lado, essa ação é o produto simples e direto de dois agentes, um homem e uma mulher que misturam uma certa massa de sêmen e sangue menstrual por meio de repetidas relações sexuais. Por outro, porém, não se pode saber o que é um feto, porque ele se oculta, invisível e silencioso, dentro do corpo de uma mulher. Invisível, ele escapa à fonte primária do conhecimento para os Piro, a visão; silencioso, escapa à fonte secundária, a fala. As pessoas precisam esperá-lo "surgir", gishpaka. Somente quando o bebê nasce é que ele pode ser conhecido. $O$ genitor e a genitora são os agentes de seu vir a ter um corpo; mas o feto é o agente de seu próprio nascimento. Os bebês "surgem de dentro", ativamente; eles não são passivamente "paridos" ou "dados à luz".

O feto só pode ser conhecido após ter emergido espontaneamente, e somente então pode-se dar uma resposta satisfatória à questão crucial:

\footnotetext{
* N.T. - A primeira glosa corresponde ao inglês "that which is being made to have a body"; na segunda, traduzimos "to embody" pelo neologismo "encorporar", visto que "incorporar", "encarnar", ou mesmo "corporificar" são diversamente inadequados.
} 
“Ele é Humano?" O recém-nascido é inspecionado visualmente em busca de evidências de sua identidade. M uitos fetos, ao emergirem, revelam-se não-humanos: formaram-se como jabotis, peixes, ou "algum animal que não reconhecemos". Eles não têm futuro no mundo da Humanidade, e são expulsos do espaço humano o mais rápido possível. A maioria dos fetos, entretanto, revela-se espontaneamente como humana. Se as pessoas que assistem ao nascimento concordarem que se trata de um novo humano, então o pai (se estiver presente) deve partir em busca de um não-parente para perfazer a Humanidade do novo humano.

$\mathrm{O}$ ato do nascimento, $\mathrm{O}$ "sair", não estará completo até que todo o feto tenha emergido. Isso significa que aquilo que, em inglês, se costuma chamar de "afterbirth" [placenta, secundinas], e que popularmente se imagina ser parte da mãe, os Piro afirmam enfaticamente ser parte do feto/bebê: a placenta, geyonchi, é uma parte do corpo do feto. Uma criança só é dita ter nascido quando tudo dela emergiu, inclusive o cordão umbilical e a placenta. Tal unidade é extremamente importante: a criança recém-nascida é uma unidade completa de "bebê" + cordão umbilical + placenta. Ela é, por assim dizer, um feto desenvolvido no tempo e no espaço, a partir de sua condição prévia de auto-involução dentro do útero materno. Alguém chega, então, para cortar o cordão umbilical, cortando, literalmente, o recém-nascido em duas metades, separando-o de si mesmo.

N esse ato - o corte do cordão - está contida toda a ontologia dos Piro. Para entendê-lo, é preciso explorar os dois modos pelos quais eles se reconhecem como humanos. Os Piro se chamam a si mesmos de yine, "Humanos"; mas eles se chamam entre si de nomolene, "meu parente". Em geral, os dois termos são co-extensivos: ser yine é ser nomolene de outros yine; ser Humano é ser parente de outros Humanos. M as em certos momentos críticos, é preciso que se achem yine que não sejam nomolene. O parto é um desses momentos.

A pessoa que corta o cordão umbilical do recém-nascido separa este em dois: um Humano, yineru; e um Outro, geyonchi, a "placenta". Ao realizar esse ato, tal pessoa entra em uma nova e poderosa relação com o novo Humano. Ao mesmo tempo, ela estará afirmando sua identidade como Humano e como não-Humano perante os pais da criança.

Esse momento é muito complexo; vejamos bem o que se passa ali. Um novo Humano surgiu no mundo dos Piro. Para se tornar completamente Humano, ele deve ser cortado ao meio. Mas, para cortá-lo ao meio, é preciso achar um Humano disposto a assumir que ele mesmo ou ela mesma não é completamente Humano aos ol hos dos pais do novo Huma- 
no. Essa pessoa deve aceitar ser vista como diferente por esses Humanos. Em suma, ela deve estar disposta a assumir o papel de Outro (i.e. de não-Humano) perante esses outros Humanos.

O que faz uma pessoa gimole ("parente") de outra é a mútua manifestação de nshinikanchi. Isso se realiza, antes de mais nada, pela mútua acessibilidade derivada da co-residência em uma aldeia (ver Gow 1991). $M$ as isso também se traduz no uso de termos de parentesco e no discurso polido. Qualquer conversação entre os Piro envolve necessariamente o uso de termos de parentesco, pois estes implicam a existência de relações específicas entre os falantes ${ }^{12}$. Quando dois desconhecidos se encontram, ou estabelecem imediatamente os termos de tratamento apropriados, ou se ignoram por completo.

A convocação de um cortador de cordão umbilical é, assim, um momento delicado, pois o pai da criança deve ir até alguém, dirigir-se a essa pessoa por um determinado termo de parentesco, para logo em seguida negar o parentesco suposto pelo termo, com o pedido de que corte o cordão do recém-surgido, isto é, de um ser em via de se tornar parente do pai.

Tão logo o ato é consumado, tudo se estabiliza, pois seus protagonistas entram em uma rede de novas relações baseadas nele. A pós ter tido sua condição de nomolene negada pelo pai da criança, o cortador do cordão torna-se nkompate (se homem) ou nkomate (se mulher) ${ }^{13}$ dos pais, e nustakjeru da criança (recíproco: nustaploolu). Esses termos substituem os termos de parentesco tanto na referência como no vocativo, e definem uma espécie de hiperparentesco, marcado por uma intensificação da memória e do respeito que caracteriza as relações entre parentes.

Tanto quanto eu saiba, ninguém jamais se recusa a ser o cortador do cordão umbilical de uma criança recém-nascida, pois receber tal pedido é uma honra. $\mathrm{N}$ a verdade, é mais fácil al guém se ofender por não ter sido chamado. O problema existencial do pai não está na resposta que venha a receber, mas na própria enunciação do pedido. Este deve começar pressupondo o nshinikanchi e terminar negando-o. É como se o pai dissesse: “M eu parente, venha rápido deixar de ser aparentado a mim!" Posto desta forma, o dilema do pai de um recém-nascido é muito semel hante ao dilema do incesto: ele é algo difícil de se falar.

\section{A fala torna os Outros possíveis}

Na verdade, há um bom motivo para ser o pai a pessoa que faz o pedido: ele é al guém que, tempos atrás, já deu fim ao incesto, mediante um certo 
uso da palavra. Esse uso envolve um modo especial de falar, que se desenvolve dentro dos homens na adolescência.

Com a puberdade, o corpo de um jovem incha e cresce com sangue. Este sangue é endógeno, desenvolvendo-se dentro dele. A pós ter estado lentamente crescendo graças à comida ingerida durante a infância, o menino atinge finalmente um tamanho a partir do qual começa, repentina e dramaticamente, a intumescer-se. Até esse momento, ele havia sido um receptor, geralmente passivo, de alimento e de outros cuidados; mas agora, um órgão seu começa a crescer e a se tornar oco, e a secretar substâncias potentes. Tal órgão é a garganta, e a substância potente por ele secretada é o riso (gislunota, "sua voz se quebra, se modifica, na puberdade"). À proporção que a garganta do rapaz se avoluma, ele vai-se tornando capaz de dar a gargalhada alta e rascante característica dos homens adultos.

Esse riso é uma coisa poderosa: ele é a condição do meyiwlu, "farrear, divertir-se, festejar". Os bons líderes são conhecidos por sua gargaIhada, que se opõe ao wamonchi, "tristeza, pesar". Mas a responsabilidade principal pelo riso cabe aos adolescentes. As pessoas mais velhas lamentam a ausência dos jovens quando estes estão longe, na escola, dizendo: “a aldeia está tão triste agora, só há velhos como nós, gente que não quer fazer nada, que não tem vontade de se divertir". Elas esperam ansiosamente a volta dos rapazes, para que a vida volte a se animar.

Os rapazes estão à procura de ganurune, "cunhados". Um ganuru é alguém exatamente como você, mas que, por definição, é um outro para você. O que os rapazes estão procurando são Outros humanos. A alegria que esses adolescentes dão às pessoas mais velhas está, em parte, na destruição do nshinikanchi, da "memória", por eles realizada14.

A alegria tumultuária e contagiosa dos rapazes faz deles mshinikatu, "descuidados, esquecidiços, sem nshinikanchi”. Em seus gracejos recíprocos, eles se interpelam pelo termo panu, "cunhado". Panu é uma palavra complexa. Trata-se de uma contração de panuru, "teu cunhado (de um homem)" ou "teu marido (de uma mulher)". À primeira vista, ambas as traduções são algo problemáticas quando as aplicamos a panu: quem é o "tu" a quem se fala? Se panu é uma contração de "teu cunhado" , então o "tu" é o próprio eu que fala - " teu cunhado" sou eu mesmo; mas isso equivaleria a afirmar uma identidade entre os ganurune [cunhados], o que contradiz a definição avançada acima. Por outro lado, se panu é uma contração de "teu marido", então o "tu" da fórmula é uma terceira pessoa, a saber, a irmã do falante. Nesse caso, os dois ganurune estariam se tratando por uma contração do termo que usariam para se 
referir um ao outro ao falar a suas próprias irmãs. E este parece ser o caso, pois um dos métodos clássicos de se provocar uma mocinha é dizer-Ihe: "Gapokatka panuru!", "Olha aí teu marido chegando!", quando um homem repugnante à menina se aproxima15.

Como Lévi-Strauss e outros já observaram para vários sistemas de parentesco das terras baixas sul-americanas, também para os Piro a "cunhadez" ["brother-in-law"-ness] é uma forma logicamente primária. "Marido" e "mulher", enquanto termos específicos de parentesco, são derivados do termo primário ganuru. A irmã do ganuru é uma ganunro potencial, uma "cunhado feminina/esposa"; e é através do estabelecimento de relações mútuas de ganuru entre os rapazes que estes conseguem suas ganunro potenciais, e as moças seus ganuru potenciais.

Os Outros abundam no cosmos, e as relações dos Piro com muitos destes Outros correspondem àquilo que Viveiros de Castro chamou de "afinidade potencial" 16. A Alteridade não está, de fato, em falta no mundo piro; mas os rapazes devem produzir Alteridade a partir do campo dos parentes, dos nomolene. Eles precisam transformar um outro Humano em algo quase, mas não completamente, idêntico a eles próprios: um ganuru. Precisam encontrar, dentro do campo da identidade (os Humanos) aquela pequena diferença que permitirá à sua sexualidade assumir uma forma social. Como eu disse, o incesto é indizível, e assim essa "alterização" de um Humano se caracteriza por uma intensificação da fala, possibilitada pela maturação de um órgão.

As meninas, durante a adolescência, também encorpam devido ao sangue, que faz um órgão interno crescer e secretar uma substância potente. A vagina intumesce e produz sangue menstrual (tuxrewata, "ela menstrua pela primeira vez"). Isso faz com que tais meninas se tornem mais sedentárias, restringindo-se à casa dos pais. "Gitoko twa", "Ela fica em casa", diz-se dessas meninas. Elas se tornam o objeto do desejo sexual dos rapazes, dos ganurune de seus irmãos, que acorrem a suas casas a ver se conseguem conversar com elas, cair-Ihes nas graças e dormir com elas. É sempre um ganuru que faculta a um rapaz o acesso a uma dessas meninas, e é como ganuru, por sua vez, que este último espera ser visto por ela.

N esse momento da vida, o foco está na garganta do rapaz e na vagina da moça. Para que se atinja a próxima etapa da sexualidade, é preciso que a boca da moça e o pênis do rapaz sejam ativados. Aqui, a iniciativa é da boca: uma moça recém-púbere é alguém que acaba de se tornar capaz de produzir grandes quantidades de cerveja de mandioca, sendo especialmente habilitada ao trabalho de mastigação da batata-doce que ativa a fermentação da bebida. Abastecidos de cerveja, seus pais podem 
agora receber muitos convidados, que acorrem às suas casas para beber. Bêbadas, as pessoas brincam e riem, e os rapazes se tornam "descuidados, sem-vergonha" - em outras palavras, eles solicitam a cooperação das moças adolescentes em sua busca de satisfação sexual.

Um rapaz e uma moça encontram-se, finalmente, dentro do mosquiteiro da moça, acionando então a última parte da equação, o pênis do rapaz. Divertindo-se dessa forma, em especial quando o fazem regularmente, eles misturam suas substâncias sexuais, o sêmen e o sangue menstrual, dentro do corpo da moça. "Casos" fortuitos, dizem os Piro, podem levar à gravidez e ao nascimento de crianças ${ }^{17}$; mas é o ritmo regular e prolongado de relações sexuais entre adultos plenos que "realmente" faz filhos.

Como já discuti em detalhe alhures (Gow 1989; 1991), o casamento baseia-se em um ajuste equilibrado entre, de um lado, o trabalho produtivo, e, de outro, o desejo oral e sexual. O casamento é o lugar onde os corpos de um homem e de uma mulher podem, com efeito, ajustar-se reciprocamente. Há uma canção de amor feminina que manifesta o ideal da sexualidade adulta: Yanasa shikale, "Cantar de A miga"18, que diz o seguinte:

“Eu tenho uma boceta grande,

E o meu marido um pau grande;

Tu tens uma boceta grande,

E o teu marido um pau grande".

A imagística altamente condensada da canção afirma que as boas relações conjugais dependem da compatibilidade entre marido e mulher quanto a seu desejo sexual19. Um bom casamento é uma relação de abundância voluptuosa e de crescente compatibilidade mútua.

O casamento caracteriza-se por uma transformação da linguagem. O homem, ao casar, pára de falar direta e normal mente com os pais de sua esposa, em particular com a mãe dela. A comunicação entre um genro e sua sogra recorre ao registro vocal de respeito intenso, com emissão alta e aguda, ou então se faz de modo indireto, através da mediação da esposa/filha. Genro e sogra são kpashiru/kpashiro, "reverenciados-proibidos" um para o outro. As mulheres nunca se esquecem de seus genros, nem os genros de suas sogras. Essa intensa memória mútua é marcada por um mútuo silêncio. Em contraste, marido e mulher "esquecem-se" um do outro. As únicas formas vocativas para "esposa" e "esposo" são klojta e klujta, "como-é-mesmo-o-nome", "coisinha", "isso aí". As únicas 
relações que permanecem idênticas após o casamento são aquelas entre "cunhados" [siblings-in-law]: esquecidas desde o início, esse esquecimento não precisa ser lembrado.

\section{A transformação ampliada}

J á explicamos as implicações do intercurso sexual, da gravidez e do nascimento de um filho. Resta agora explicarmos a gênese do nshinikanchi na criança que nasceu e as conseqüências desse processo.

Em seus primeiros meses de vida, um bebê está perigosamente ligado ao interior do corpo dos pais, devido à sua identidade com os fluidos sexuais destes, que devem observar numerosas restrições de comportamento até que a criança atinja um certo nível de autonomia pessoal (ver Gow 1989; 1991). É quando pára de mamar e aprende a andar que a criança começa a desenvolver nshinikanchi, e portanto começa a chamar aqueles que cuidam dela por termos de parentesco

U ma vez completamente desmamada, a criança é alimentada com "comida legítima", a comida que todos os Piro comem (uma combinação de carne de caça e banana ou macaxeira). Este alimento, fornecido pelos pais e, através deles, por todos os parentes adultos, preenche essa nova interioridade formada pelas entranhas da criança. Satisfazendo sua fome, o alimento dirige a atenção da criança para o exterior, para o campo social dos "alimentadores", isto é, daqueles que "viram aflição" na criança.

$\mathrm{Na}$ condição intra-uterina, o feto não possui interior ou exterior: ele está embrulhado em sua placenta, isto é, em suas próprias entranhas. Depois do nascimento, o bebê se vê separado da placenta, processo que Ihe dá um interior e um exterior. Esse interior vazio, causando-Ihe fome e sofrimento, pode ser enchido de comida, a qual, ao satisfazer um desejo, transforma-se em nshinikanchi no exterior do corpo, faculdade de que o bebê dá provas ao se mostrar atento e atraído pelos que o alimentam. Tal nshinikanchi manifesta-se primordialmente no uso seletivo de termos de parentesco, isto é, na linguagem.

Por que as pessoas alimentam e cuidam de bebezinhos? Elas o fazem porque eles são kwamonuru, "bonitinhos, tristes, coitados, pobrezinhos". Isto suscita getwamonuta, "ver a tristeza, pena, desamparo, graciosidade de alguém", o que é um aspecto do nshinikanchi. Getwamonuta, "enxergar a aflição", faz com que os parentes mais vel hos busquem satisfazer os desejos do bebê, o que leva à formação de nshinikanchi à medida que ele vai crescendo. 
É tentador sugerir que os bebezinhos são kwamonuru, "tristes, angustiados, desamparados, mimosos" porque eles perderam seu "outro", a placenta. Nos adultos, a causa primária de wamonchi, "pesar, tristeza, desamparo", é a morte de parentes próximos. Assim, seria razoável supor que o bebê está de luto pela perda da outra metade de si. Mas isso não parece correto, visto que wamonchi é, nos adultos, um afeto decorrente do nshinikanchi, faculdade que os bebês ainda não desenvolveram. Além do mais, a placenta não é algo a que o bebê fosse "relacionado" ela e ele eram uma coisa só.

Penso que o que une o adul to enlutado e o bebezinho não é tanto a perda que partilham, mas sua comum solidão humana. $\mathrm{O}$ adulto de luto perdeu um parente querido, e assim foi deixado sozinho, abandonado20. Um bebezinho, graças à decisão tomada no momento de sua vinda à luz, é yineru, "Humano". Ele é um Humano que se vê em uma condição dolorosa de singularidade, a condição de não ter ninguém capaz de aplacar seus desejos. O que lhe falta é nomolene, "meus parentes". É nisso que ele se assemelha a um adulto enlutado, e é tal dolorosa singularidade que é "vista" pelos outros.

O pré-requisito para que o bebê tenha parentes, pessoas para quem se volta sua consciência, é a perda de parte de seu Eu originário, a saber, seu Outro Primordial. Este outro eu é seqüestrado por um Humano que se torna o primeiro outro Humano do bebê, o nustakjeru, "meu cortadordo-cordão-umbilical". Como vimos, tal pessoa, aquela que permite que a criança tenha parentes, é definida como não-parente pelos pais da criança. Esse Humano permite à criança ser um Humano para outros Humanos, isto é, para seus nomolene, seus "parentes prospectivos" [kinspeople-to-be].

Perdendo o geyonchi, a nova pessoa Piro acha o nshinikanchi, e se volta para outros Humanos. N shinikanchi é uma faculdade evidente que pode ser vista no desejo que um outro Humano manifesta de estar com o sujeito, e que pode ser ouvida na fala respeitosa desse outro. Como observei anteriormente, o nshinikanchi manifesta-se pela co-presença mútua, pela co-residência em uma mesma aldeia21. Com o passar do tempo, o nshinikanchi se desenvolve e amplia, englobando cada vez mais gente. À proporção que as pessoas vão envelhecendo, elas se tornam o foco das escolhas residenciais feitas pelos mais jovens, de tal forma que as aldeias crescem à volta do nshinikanchi dos velhos, por intermédio do nshinikanchi de seus parentes mais moços. Em 1995, a maioria dos adultos residentes em Santa Clara (população total: 150) podia dar como razão principal para viver ali o fato de suas relações com a vel ha Clotilde Gordón, 
que, com oitenta anos, era a única pessoa a quem todos eram explícita e inequivocamente aparentados 22 .

O nshinikanchi se desenvolve e manifesta como uma expansão do campo social imediato, a ampliação das aldeias, a multiplicação dos parentes. Isso se dá, por assim dizer, como um puro produto do tempo, da experiência vivida. Nshinikanchi é algo que se desenvolve espontaneamente dentro da pessoa como uma resposta à fome saciada, mas ele leva à multiplicação e ramificação dos laços entre os viventes.

É, assim, o nshinikanchi que envolve a cena por onde começamos este artigo, com os vel hos Piro contando tsrunnini ginkakle, "histórias dos antigos", para seus netinhos. Uma longa vida culmina na narração dessas histórias, a emissão dessa fala que, provindo dos mortos há muito olvidados, "não nos chegam, a rigor, de lugar nenhum" (Lévi-Strauss 1964:26). E ao ouvirem atentamente tais histórias, as crianças mostram estar desenvolvendo nshinikanchi, nesse processo contínuo de transformação da consciência que é o parentesco piro.

\section{Singularidade e multiplicidade}

Voltemos à história dos antigos sobre o "Nascimento de Tsla". Como já vimos, Tsla é efetivamente um kgwiyaklewakleru, um "ser miraculoso", da perspectiva dos xanikaka yine, o "povo de hoje em dia", ou seja, os Piro atuais.

Tsla emergiu espontaneamente do útero de sua mãe despedaçada, seguido por seus "irmãozinhos", os muchkajine. Ou seja, ele não somente era um agente hipersocial, falando ainda dentro do útero materno (e portanto já completamente Humano antes do nascimento), mas ele também nunca se separou de seu Outro Primordial, a placenta. Com efeito, Tsla manteve junto a si esse outro, sob a forma de seus irmãozinhos e companheiros, os muchkajine, que emergiram do útero depois dele ${ }^{23}$. Tsla realiza um curto-circuito radical de todo o parentesco piro, ao se autosuscitar espontaneamente como um agente social completo. Ele é, assim, o criador miraculoso de si mesmo, e portanto o criador miraculoso do mundo. Não existe nada como ele no mundo vivido contemporâneo dos Piro.

Bem, talvez exista algo como ele. Os Piro são como ele. Tsla é enfaticamente um yineru, um Humano, um Piro. Como me disse um homem: "Tsla era baixo e de pele escura, exatamente como nós". Seus irmãozinhos, em troca, não são H umanos: eles são muchkajine, "os Brancos de 
antigamente, os primeiros Brancos". Segundo as histórias dos antigos, Tsla e os muchkajine, após ouvirem uma ave que agourava a morte, foram embora rio abaixo, muito longe, "ninguém sabe para onde", dizem os narradores. Atrás de si, eles deixaram os yine, os Piro. Tsla os fez de argila de olaria, dando-Ihes vida com um sopro. Tsla Ihes disse: "Fiquem nesta terra, agora. Multipliquem-se. Multipliquem-se tendo crianças boas e inteligentes. Cuidem bem delas. Trabalhem. Façam roças. Derrubem árvores. Plantem banana, mandioca, cana." (M atteson 1951:52)

Os Piro são como Tsla. Como ele, eles fazem Humanos. Eles modelam novos viventes, animando-os com sua fala. Mas, ao contrário de Tsla, os Piro não modelam novos viventes através de poderes singulares, "miraculosos", nem os animam por meio de um sopro poderoso. Eles dão origem a seu mundo através da multiplicidade, seguindo o consel ho miraculoso de Tsla para "tornarem-se muitos".

Enquanto Tsla foi capaz de manter o outro primordial junto a si sob a forma de seus irmãos mais moços, o bebê Piro precisa perder seu outro primordial para poder substituí-lo pelos nomolene, "meus parentes", uma multiplicidade de outros Humanos diferenciados. A raiz mole- significa "parente", "amontoar uma quantidade de coisas semelhantes" e "dez". Ela significa, portanto, a reunião de elementos que são separadamente semelhantes em uma multiplicidade de elementos idênticos: "parentes", "coisas", "números" (i.e. os dígitos das mãos). Aquilo que Tsla podia fazer sozinho, os Piro devem fazer através de sua própria multiplicidade 24.

Tal multiplicidade conduz ao valor supremo dos Piro: gwashlu, o "viver bem". O termo significa, literalmente, "morar e não fazer mais nada"; ele se refere à tranquilidade do dia-a-dia da vida na aldeia, a uma vida marcada pela ausência de qualquer tristeza, insatisfação ou ressentimento que leve uma pessoa a querer se mudar. Esse valor se baseia na orquestração dos ciclos de vida de pessoas diversas pelo sexo e a idade, de tal forma que os acontecimentos específicos da vida de uma pessoa (nascimento, puberdade) ramificam-se para fora, transformando a vida de outros, e sendo transformados, por sua vez, por esses outros.

O que teríamos de definir como parentesco, para os Piro, é esse "viver bem" 25 . Ele se destaca contra um fundo cósmico de Alteridade, um mundo de Outros com quem os Humanos de uma aldeia piro mantêm uma variedade de relações, mas com quem não se pode "viver bem". Dentre esses Outros, os mais íntimos são os mortos, ex-Humanos que tomaram o caminho da Alteridade. M eu finado compadre Artemio Fasabi, da aldeia de Santa Clara, assim exprimiu certo dia a essência do "vi- 
ver bem": "Eu nunca poderia ir viver longe daqui. Isso seria o mesmo que morrer. O que é a morte, senão que você nunca mais poderá ver seus parentes, seu pai, sua mãe?"

Não há, obviamente, nenhuma razão para que fiquemos por aqui; mas uma história deve parar em algum lugar, e assim este é o fim de minha análise. Como dizem os narradores das tsrunnini ginkakle: "Seyokatka", "Isto é tudo, por ora”, na esperança de que mais tarde, amanhã, outro dia, a gente recomece de onde se parou.

\section{Conclusão}

À guisa de conclusão, gostaria de retomar rapidamente al gumas das implicações mais gerais de minha abordagem do parentesco piro e da consciência humana. Marylin Strathern observa, de uma perspectiva pósmoderna, que "[p]ara o antropólogo moderno, os fatos do parentesco eram ao mesmo tempo fatos naturais e fatos culturais ou sociais" (1992:46).

Isso levou os antropólogos ocidentais a projetar sobre todas as culturas que estudam certas formulações especificamente ocidentais sobre a "natureza" e os "Iaços naturais" 26. Foi contra tal projeção indevida que muitos críticos da análise modernista do parentesco se levantaram; um dos mais eminentes desses críticos, David Schneider, chegou mesmo a proclamar que “o 'parentesco' [...] é um não-objeto, visto não existir em nenhuma cultura conhecida do homem" (1984:vii).

Embora eu seja geralmente simpático a tais críticas, creio que o verdadeiro problema não está aí. O verdadeiro problema é muito mais profundo; ele diz respeito ao modo específico pelo qual a antropologia moderna definiu o social ou o cultural em oposição ao biológico. As análises do parentesco começaram pondo a sociedade/cultura como um domínio de objetos e de métodos metafisicamente distinto de seu "outro", a natureza. Assim, tais análises se viram obrigadas a demarcar rigidamente a fronteira entre os dois domínios, abandonando à biologia muito do que elas gostariam de explicar. Pior ainda, o estudo da natureza viva terminou por se reinfiltrar nessas análises, pois muitos antropólogos vieram a confundir a ciência da biologia com o objeto desta ciência, como se constata quando se os ouve falar em "parentes biológicos" ou em "fatos biológicos". Isso sugere que a abordagem sociocultural sempre esteve fadada ao fracasso, já que os antropólogos atribuíam uma auto-evidência ou uma transparência à construção dos argumentos dos biólogos que eles não reivindicavam para os seus próprios. 
A o começar minha análise, neste artigo, por um problema de biologia, o problema da consciência e da linguagem dos humanos, procurei evitar essa armadilha. Se, como argumentei, o parentesco piro é feito de consciência e de linguagem, então ele é um fenômeno biológico - um daqueles fenômenos biológicos, aliás, sobre os quais os próprios biólogos admitem saber muito pouco.

Começando por um problema biológico, além disso, não fiz senão seguir os passos de Freud. Para Freud, o problema da consciência humana sempre teve suas raízes nas ciências naturais, e especificamente na biologia. Por mais inadequado ou absurdo que seu trabalho nos pareça hoje, Freud sempre esteve preocupado em ajustar as descobertas da psicanálise à biologia que ele conhecia. M uito do que soa esquisito ou risível em Freud deriva da igualmente esquisita e risível biologia de sua época, anterior ao encontro de Mendel e Darwin na Nova Síntese. A única psicanálise contemporânea que vale a pena ler, aliás, é aquela que mantém tal laço com a dinâmica da ciência biológica.

Freud também era um leitor voraz de antropologia, e sempre procurou ligar seu trabalho às descobertas dessa disciplina. Tratava-se, mais uma vez, da antropologia de seu tempo e lugar. Um dos maiores problemas da antropologia de Freud era o seu "evolucionismo social" e a conseqüente assimilação dos selvagens das terras distantes aos antepassados remotos dos europeus, em uma tentativa de remediar, com o que se sabia dos primeiros, a ignorância sobre os segundos, e reciprocamente. Isso fez com que Freud (e tantos outros de sua época) reduzisse ambos a uma massa simples e comum, o que autorizou o tratamento de todos os mitos dos selvagens como variantes de um único mito, o mito grego de Édipo, que se tornou o mito de origem da Humanidade. Mas, mais uma vez, a única psicanálise contemporânea que vale a pena ler é aquela que está comprometida com a dinâmica da antropologia.

Sabemos hoje muito mais sobre os mitos, graças às monumentais Mitológicas de Lévi-Strauss. Este autor mostrou claramente que cada mito, em cada evento narrativo, é único, irredutível a uma versão mais antiga ou mais autêntica; ele mostrou também que os mitos de Édipo são apenas um conjunto dentro de uma multidão. Todos os mitos, entretanto, estão ligados sistematicamente por meio de um sistema multidimensional de transformações. Tal sistema, argumenta Lévi-Strauss, é o próprio pensamento humano buscando apreender as transformações temporais do mundo onde ele se acha mergulhado27. No "Finale" de L'Homme Nu, Lévi-Strauss recusa o reducionismo simplista da psicanálise freudiana clássica, escrevendo: 
"M enos confusões teriam sido suscitadas pela noção de natureza humana, que persisto em empregar, se se tivesse advertido que não a concebo como um edifício de estruturas acabadas e imutáveis, mas sim como matrizes a partir das quais se engendram estruturas que, embora pertencendo todas ao mesmo conjunto, não permanecem necessariamente idênticas ao longo da existência individual ou, no caso das sociedades humanas, em todo tempo e lugar" (1971:561).

Creio que a maioria dos biólogos reconheceria seu objeto de pesquisa muito mais nessa definição de natureza humana que na "natureza" e na "biologia" que têm freqüentado, até o presente, as páginas de tantas descrições antropológicas do parentesco. Essa é uma definição, ademais, que nos permitiria evitar as implicações muito discutíveis de uma concepção da Humanidade que atribuiu a unidade à biologia e a variação ao "domínio" ou "nível" ontologicamente separado da "cultura" ou da "sociedade". Seguindo a perspectiva de Lévi-Strauss, como fiz aqui, poderemos compreender a variabilidade dos sistemas de parentesco humano como produto da natureza humana; além disso, se eles são todos estruturas que pertencem a um mesmo conjunto, isso nos garante sua inteligibilidade. Como etnógrafo, posso compreender o parentesco piro, e comunicar esta compreensão, porque sua inteligibilidade é a de um modo vivido da consciência humana.

Recebido em 14 de maio de 1997

A provado em 10 de julho de 1997

Tradução de Eduardo Viveiros de Castro

Peter Gow é professor da Universidade de Manchester. Em 1996, foi professor-visitante do Programa de Pós-Graduação em Antropologia Social (PPGAS) do M useu Nacional/UFRJ . Publicou Of M ixed Blood: Kinship and History in Peruvian Amazonia, além de artigos em revistas especializadas. 


\section{Notas}

1 O trabalho de campo no Bajo Urubamba foi financiado pelo Social Science Research Council (Grã-Bretanha), pela Nuffield Foundation e pela British Academy. Por suas sugestões, eu gostaria de agradecer a Christina Toren, Heonik Kwon, J ean Lave, Borut Telban e Andrew Holding.

$2 \mathrm{O}$ argumento de Haraway parece sugerir que as respostas a tais perguntas são auto-evidentes - como se todos nós já as soubéssemos. Veja-se, entretanto, o artigo de Laura Miller, "Women and Children First", para uma crítica demolidora a esse estilo "professora careta" como sendo o inimigo mortal de toda investigação imaginativa. Nos passos de Miller, poderíamos ver Haraway como a professora puritana dos filmes sobre o Velho Oeste, que chega para expulsar as "más meninas" (as primatólogas) da cidade. Assim, alertada por Haraway, qualquer pessoa de bem poderá constatar que essas primatólogas andam em péssima companhia: macacos, primatas antropóides [apes] — e homens. Isso é lamentável, pois quantos cientistas sociais estarão dispostos a parar para ler The Chimpanzees of Gombe de Goodall, depois de Haraway Ihes ter dado uma excelente razão para não ler esse livro?

3 Essas questões exigiriam, obviamente, uma discussão muito mais extensa, tanto mais porque os argumentos de Wilden, Rubin e Strathern sobre o assunto receberam pouca atenção na literatura subseqüente. Tal discussão implicaria uma reflexão crítica sobre o papel do "dom" maussiano nos trabalhos de Lévi-Strauss sobre o parentesco e sobre sua influência no conceito lacaniano de "simbólico".

4 O estudo de Mimica sobre os Iqwaye e a análise de Toren sobre o amor em Fiji foram fontes de inspiração fundamentais para o presente artigo.

5 Admito estar aqui fazendo uma certa prestidigitação. De todos os mitos piro, "O Nascimento de Tsla" é o que mais de perto se aparenta às narrativas genéticas de minha própria cultura; tomei, assim, tal atalho por conveniência expositiva. Contudo, poderia ter começado por qualquer mito piro, que chegaria à mesma conclusão (algo que não posso provar aqui, mas apenas, mais uma vez, prestidigitar). Na verdade, o presente artigo deriva de uma análise de outros mitos piro: "Como o fogo foi encontrado", "Klana pinta o rosto da Lua" e "O homem que virou um queixada".

6 Argumentei em outro trabalho (Gow 1991) que os velhos têm essa capacidade de dar forma a essa fala especial por causa de sua posição existencial como gente que "sabe onde quer morrer", isto é, que está completamente resignada diante da morte próxima. 
7 Há outros termos de parentesco, como wiwi e shte, "parente mais jovem", magi, "cunhada", e panu, "cunhado". Mas estes são, por razões óbvias, pouco usados por crianças pequenas.

8 O mito piro de origem das manchas da lua, apesar de sua semelhança com outros mitos ameríndios sobre o tema, destaca-se por não mencionar o motivo do incesto.

9 Os mashko são usualmente identificados aos povos de língua harakmbút do rio Madre de Dios, como os Amakaeri.

10 A passagem leva a crer que a sugestão partiu de M atteson, não de um Piro.

11 O marido-J aguar pode ser ou não o genitor de Tsla. Em al gumas versões ele é, em outras fala-se em um genitor humano, e muitas nada dizem a respeito. A questão não tem muita importância, por motivos que se tornarão claros mais à frente. Mas o J aguar é indubitavelmente o pai de Tsla. [N.T. - O autor está aqui contrastando genitor e pater, ou "pai biológico" e "pai social".]

12 Uma pessoa mais velha pode se dirigir a outra mais moça pelo nome ou apelido, alternativamente ao termo genérico "parente mais jovem", mas esta última deve responder utilizando um termo de parentesco.

13 Esses termos são estendidos aos cônjuges dos cortadores.

14 N os funerais piro, esses adolescentes são convidados a beber e “divertirse". Durante um velório, os vivos estão atormentados pela memória (nshinikanchi) aterrorizante do morto, assim como (e porque) o morto se lembra dos vivos. Se um velório é marcado por uma tristeza excessiva, costuma-se culpar os parentes enlutados, dizendo que eles não providenciaram álcool em quantidade suficiente para que os jovens se divertissem - o potencial de exuberância dos rapazes não foi realizado.

15 Esta análise encontra eco no apelido usado comumente pelos Piro para falar dos Campa-Asháninka vizinhos: Pishinto, que é a forma campa para "tua filha". Isto seria uma contração da frase: "Pamenero pishinto!", “Dá-me tua filha!", gracejo-padrão que marca as interações de homens Piro e Campa.

16 Um bom exemplo disso são os Conibo, de língua Pano, vizinhos setentrionais dos Piro do Urubamba. Os Piro chamam esse povo de Chayiko, "muito chayi" (da palavra conibo chai, que corresponde ao piro ganuru). Ou seja, os Piro chamam os Conibo pelo aumentativo de um termo que os Conibo usam para falar deles Piro. Os Conibo são, assim, os “afins potenciais plenos" dos Piro. Eles são também fortemente endógamos; não sei de nenhum intercasamento Piro-Conibo. 
17 As crianças nascidas de relações ocasionais são chamadas "filhas do vento". Uma mulher assim me falou afetuosamente de uma de suas filhas, enquanto Ihe afagava a cabeça: “Ela é só uma filha do vento. Nunca vivi com o pai dela, só trepei com ele em festas. Sei lá onde ele anda agora".

18 A palavra yanasa foi-me explicada como se referindo a "uma mulher mestiza, amiga de uma mulher Piro".

19 As canções de amor piro são marcadas por um "deslizamento" complexo da posição de sujeito, de tal forma que o ouvinte preferencial deve deduzir onde se colocar no jogo de deslizamento do sujeito. $\mathrm{O}$ "tu" da Yanasa shikale é a "amiga", mas a canção é dirigida aos ouvidos do marido da cantora. Trocando em miúdos, a cantora diz ao marido que eles formam um casal sexualmente compatível, e portanto que ele não tem por que desejar outras mulheres que, por sua vez, são sexualmente compatíveis com seus próprios maridos. Ver Gow (1991) sobre as relações entre compadres e comadres.

20 Ver Gow (1991) para uma discussão das relações complexas de abandono e solidão entre parentes vivos e mortos.

21 Viver longe dos parentes é "esquecer-se" deles, e todo esquecimento entre parentes leva ao ressentimento e, em última análise, à fragmentação das aldeias. A mbos os resultados têm a qualidade negativa do que é mshinikatu, "esquecidiço, desamorável, desrespeitoso, insensível".

22 Ao voltar aos Piro em 1995, após sete anos de ausência, surpreendi-me ao achar Santa Clara tão pouco mudada, apesar de todo o sofrimento causado pela guerra civil peruana nessa região e da morte de dois líderes da aldeia, entre várias outras pessoas. Tenho fortes suspeitas de que foi graças à longevidade de Clotilde Gordón que a aldeia permaneceu unida.

23 Poder-se-ia dizer que Tsla é miraculoso porque ele já tinha parentes antes mesmo de haver nascido. Essa formulação ajuda a medir a enorme distância entre as concepções piro e ocidental do parentesco.

24 Em piro, as palavras yine, "Humanos", e yineru/yinero, "Humano masculino/feminino", possuem uma característica excepcional. Yine é, tecnicamente, a forma plural da raiz nominal yi- seguida do "pluralizador"-ne, mas essa raiz nominal não pode tomar a forma singular (não existe a palavra yi em piro). Assim, as formas singulares dos Humanos (yineru e yinero, conforme o gênero) são a singularização do que é intrinsecamente um plural. Com a exceção dos "grupos nominados endógamos" (ver Gow 1991), essa situação não tem paralelo na língua piro.

25 Isso não se choca, obviamente, com a identificação do parentesco à memória, que avancei em trabalhos anteriores (Gow 1989; 1991). “Viver bem” é ao mesmo tempo o produto e o produtor da memória. 
26 Uso aqui "ocidental", em lugar do "euro-americano" de Strathern, em atenção à popularidade de que o primeiro termo goza, entre esse grupo de pessoas, como auto-identificação.

27 É significativo que a "segunda teoria do parentesco" de Lévi-Strauss, aquela dispersa em seus escritos sobre a noção de Casa, e que se desenvolveu a partir de suas reflexões sobre o mito e a temporalidade, dê muito menos peso ao paradigma maussiano do dom (ver nota 3, supra). 


\section{Referências bibliográficas}

CHENEY, Dorothy L. e SEYFARTH, Robert M. 1992. How Monkeys See the World: Inside the Mind of Another Species. Chicago: University of Chicago Press.

FOLEY, Robert. 1987. A nother Unique Species: Patterns in Human Evolutionary Ecology. Essex: Harlow.

GoodALL, Jane. 1986. The Chimpanzees of Gombe: Patterns of Behavior. Cambridge, Mass.: Harvard University Press.

Gow, Peter. 1989. “The Perverse Child: Desire in a Native Amazonian Subsistence Economy". Man, 24(4):567582.

_.1991. Of M ixed Blood. Oxford: Clarendon Press.

HARAWAY, Donna. 1989. Primate Visions. Gender, Race and Nature in the World of M odern Science. N ew York: Routledge.

LÉVI-STRAUSS, Claude. 1958 [1945].

“L'A nalyse Structurale en Linguistique et en Anthropologie". In: Anthropologie Structurale. Paris: PIon. pp. 37-62

.1964. M ythologiques: Le Cru et le Cuit. Paris: Plon.

. 1971. Mythologiques IV: L'Homme Nu. Paris: Plon.

MATTESON, Esther. 1951. "Piro M yths". Kroeber Anthropological Society Papers, 4:37-87.

. 1955. “A nalyzed Piro Text: A Boy and a J aguar". Kroeber A nthropological Society Papers, 12:22-44.
MILLER, Laura. 1995. “Women and Children First: Gender and the Settling of the Electronic Frontier". In: J. Brook e I. A. Boul (eds.), Resisting the Virtual Life: The Culture and Politics of Information. San Francisco: City Lights.

PREMACK, A. J. e PREMACK, D. 1987. The $M$ ind of an Ape. New York: Bookthrift $\mathrm{Co}$.

RUBIN, Gayle. 1975. "The Traffic in Women: Notes on the Political Economy of Sex". In: P. Rayna (ed.), Toward an Anthropology of Women. New York: Monthly Review Press. pp. 157-210.

SCHNEIDER, David. 1984. A Critique of the Study of Kinship. Ann Arbour: The University of M ichigan Press.

SMUTS, Barbara B. 1985. Sex and Friendship among Baboons. Chicago: Aldine.

STRATHERN, Marylin. 1992. After Nature: English Kinship in the Late Twentieth Century. Cambridge: Cambridge University Press.

STRUM, Shirley. 1987. Almost Human: A J ourney into the World of Baboons. New York: Random House.

TRAUTMANN, Thomas R. 1987. Lewis Henry Morgan and the Invention of Kinship. Berkeley: University of California Press.

WILDEN, Anthony. 1972. System and Structure: Essays in Communication and Exchange. London: Tavistock. 


\section{Resumo}

Este artigo analisa o sistema de parentesco dos Piro da A mazônia peruana como um sistema autopoiético, isto é, como um sistema que gera suas próprias condições de existência. O postulado teórico central é que o parentesco é um sistema de subjetividade, pois as estruturas básicas da consciência humana envolvem necessariamente a consciência de um eu em meio aos outros. Um dos objetivos aqui perseguidos é o de contribuir para que a antropologia simbólica possa voltar a fazer um uso fecundo da noção de "natureza humana". A análise parte de uma narrativa, "O N ascimento de Tsla", em que se encontram encapsulados - na mensagem como nas condições pragmáticas de enunciação desse mito - os princípios fundamentais do parentesco piro, acompanhando a ontogênese dos seres humanos e mostrando o papel constitutivo, nessa ontogênese, da linguagem e da alteridade.

\section{Abstract}

This article analyzes the kinship system of the Piro of Peruvian Amazonia as an autopoeitic system, that is, as a system which generates its own existential conditions. The central theoretical postulate is that kinship is a system of subjectivity, since the basic structures of human consciousness necessarily involve being conscious of an I amid others. One of the article's objectives is to provide schemata enabling symbolic anthropology to return to a fertile use of the notion of "human nature". The analysis departs from a narrative, "The Birth of Tsla", which encapsulates - in both the message and the pragmatic conditions of the myth's enunciation the fundamental principles of Piro kinship; this is followed by an analysis of the ontogenesis of human beings, which reveals the constitutive role, in this ontogenesis, of language and alterity. 